\title{
On English Inanimate Subject Sentences from the Perspective of Chinese Language
}

\author{
Chunlei Wang ${ }^{1 \& 2}$ \\ ${ }^{1}$ China University of Mining and Technology, Xuzhou, Jiangsu, China \\ ${ }^{2}$ Suqian College, Suqian, Jiangsu, China \\ Correspondence: Chunlei Wang, China University of Mining and Technology, Xuzhou, Jiangsu, China. E-mail: \\ zhumawang@163.com
}

Received: May 18, $2020 \quad$ Accepted: June 18, $2020 \quad$ Online Published: June 23, 2020

doi:10.5539/ijel.v10n5p53 URL: https://doi.org/10.5539/ijel.v10n5p53

\begin{abstract}
The inanimate subject sentence is sometimes called the impersonal subject sentence, which also is a unique linguistic phenomenon in English. Considering the cultural differences between the East and the West and the characteristics of English and Chinese, this kind of sentence pattern is difficult for Chinese learners. The purpose of this paper aims to address the features of inanimate subject on the basis of the analysis and research of inanimate subject sentences. English inanimate subject sentences are special linguistic phenomenon. In order to better analyze and understand inanimate subject sentences, a tentative classification and analysis is conducted on its subject types and semantic features. And more examples are demonstrated to illuminate the application of the inanimate subjects in English and Chinese.
\end{abstract}

Keywords: inanimate subject sentences, subject types, classification, Chinese translation strategy

\section{Introduction}

An inanimate subject is also called an impersonal subject. Inanimate means what is without life. An English sentence with an inanimate subject appears in written English, in which an inanimate object acts as the subject. It is an English grammar structure, and it is also a special and typical language phenomenon in English. It is quite different from Chinese sentences. Inanimate subject sentences are often related to aspects such as history, culture, and ways of thinking. Many scholars (He, 2003, 2005; Hu, 1993; Huang, 2002; Ma, 1995; Wang, 1999) in China have published magnitude of research papers on the inanimate subject sentences, though their western counterparts (Jersperson, 1951; Lewis, 1949; Leech \& Svartvik, 1974; Comrie, 1981; Quirk, 1985) dot this linguistic phenomenon analysis in their grammar or vocabulary research. The characteristics of inanimate subject sentences are analyzed from different perspectives. Some scholars analyze it from the aspect of animacy, while other scholars (Lan, 2005; Lakoff \& Johnson, 1980; Halliday, 1994) believe that metaphor is the root of the vividness and universality of inanimate subject sentences. For example, He (2003, 2005) focuses on the analysis of the implied logical and semantic relations of inanimate subject sentences, and he believes that there are many kinds of implied logical semantic relations in English sentences with inanimate subjects, including cause and effect, condition, means, concession, time, space, degree and contrast and so on, and in which that causality is most common and most complex. In the A Cognitive Analysis of English Sentences with Inanimate Subjects, Zhou (2009) analyzes the characteristics of inanimate subject sentences from the perspective of cognitive linguistics. We have learned that the inanimate subjects in English often use nouns that have a deprivation of verbs or adjectives, which makes non-personal subject highlight, concise and compact, strong objectivity, static language features prominently, and which is more in line with the thinking and cognitive characteristics of westerners that emphasize rationality and objectivity. In the Analysis of the Causes of Chinese Animate Sentences and English Inanimate Sentences, Wei (2003) believes that the objectivity expressed from English is a full reflection of inanimate subject sentences, and this objectivity is caused by English which has to externalize its logic and hypostasis. There is a strong deposit of objective consciousness in the thinking habits of British and American people, which is reflected on the way they express their language, namely the objectivity of expression.

However, not many people have studied the subject types of inanimate subject sentences, so this discourse starts from the differences between Chinese and Western thinking and the characteristics of English and Chinese, and 
then has a thorough study of subject types in order to find out some practical Chinese translation strategies.

The purpose of this paper aims to address the features of inanimate subject on the basis of the analysis and research of inanimate subject sentences. English inanimate subject sentences are special linguistic phenomenon. In order to better analyze and understand inanimate subject sentences, a tentative classification and analysis is conducted on its subject types and semantic features.

\section{The Features of Inanimate Subject Sentences}

Due to the different essential significance, nouns can be categorized by two types: animate nouns and inanimate nouns. In a sentence, a subject with a spiritual noun is called an animate subject, and a subject without life is called an inanimate subject. Generally speaking, an animate sentence is composed of 'animate noun + animate verb' and the inanimate sentence is composed of 'inanimate noun + inanimate verb'. In English, there are a large number of sentences with inanimate subjects, while in Chinese, there are more animate subject sentences that are formed by people or subjects with other living characteristics. This situation is due to different philosophical concepts, and there are great differences between the eastern and western ways of thinking. The Chinese language emphasizes the way of thinking, which is 'people-oriented' and 'everything depends on human efforts', and which can be explained through the constantly deep thinking and understanding on the connection between the man and nature since the ancient times. In addition, Han culture, emphasizes emotion and subjective consciousness, and advocates that 'man is the subject of all things', 'all things belong to me', 'all things are one with me' and so on. Han culture is good at thinking in images. In English, by contrast, people often pay more attention to natural things and features and impacts of no spirit things, which is also reflected in the habit of using inanimate nouns as subjects. That is because English culture was deeply influenced by Aristotle's formal logic and the emphasis on scientific experiments and forms in the 16th and 18th centuries. They believe that only human beings and human society can have the action represented by spiritual verbs. With the influence of European rationalism, it pays attention to objective consciousness, emphasizes rationality, and has strong logical thinking and analytical thinking ability. In terms of language and culture, English emphasizes formal integrity and emphasizes object (Seskauskiene, 2009). It often allows 'thing' to be expressed in the form of objective facts, which can be non-human words referred to as the subjects (Foley, 1997; Jesperson, 1951; Leech, 1973; Quirk, 1984). Therefore, abstract nouns or inanimate things as the subjects of sentences are widely used in English, especially in the written language, which is a typical sentence pattern in formal written English (Yule, 2014).

Moreover, from the characteristics of English language, metaphor is also a major feature of inanimate subject sentences. Cognitive linguists Lakoff and Johnson (1980) believe that metaphor is not just a form of expression but also an essential means of human thinking. It directly participates in the social cognition process and is a type of the methods that people learn more about the world. And Master (1991) considered that metaphor is the "omnipresent principle of human language". Metaphor is not only a form of expression but also a cognition phenomenon. Because of the physical experience of human beings, people always recognize things from themselves and their behaviors, such as perceptions, movements, spatial location and other specific, relatively clear structures, relatively easy to seize the field of experience. Through their analogy, to recognize and understand the relatively unfamiliar structure is rather challenging. This tool that humans use to organize knowledge is a metaphor. Lakoff and Turner's epistemological conceptual metaphor works as follows: each metaphor contains two sections, the source domain, and the target domain. The cognitive power of metaphor lies in mapping the schema structure of the source domain to the target domain. This mapping occurs at the conceptual level and is systematic (1989).

\section{Types of Inanimate Subjects}

\subsection{Vitality}

Vitality is ubiquitous in the grammar of the human language, which is reflected not only in nouns but also in verbs. Although the vitality of English verbs often changes with the change of meaning and context, this does not mean that it is not reflected in English verbs. On the contrary, in a particular English sentence, the vitality of the verb is obvious. For example, if static verbs will be replaced by other dynamic verbs in Subject-Link verb-Predicative Structure and 'There be' sentences, the vitality of these sentences is obvious. Thus, we can divide English inanimate subject sentences into two categories: structural inanimate subject sentences and of metaphorical inanimate subject sentences.

The so-called structural inanimate subject sentence refers to the sentence composed of an inanimate subject and inanimate predicate. In this kind of inanimate subject sentences, the collocation between subject and predicate is the same as that of Chinese sentences in the semantic feature of vitality, so it will not cause difficulties in understanding and using and it is easy to be mastered by English learners who are Chinese. The so-called 
metaphorical inanimate subject sentences refer to the sentence generated by the combination of inanimate subject and animate predicate, or the sentence formed by the combination of inanimate subject and inanimate predicate, but its vital semantic feature is implied in the sentence between the subject and its modifier, the former is a conceptual metaphorical sentence, and the latter is a grammatical metaphorical sentence. The collocation of subject and predicate in such sentences with inanimate subjects is opposite or different from that in Chinese sentences in the semantic feature of vitality, which is often difficult for Chinese English learners to understand and master.

\subsection{Subject Types}

As for the types of subjects, different linguists, from different perspectives, come up with different classification results: as few as three, as many as a dozen. Huang (1983) pointed out in his book Modern Chinese: From the perspective of the relationship between subject and predicate, there are three subjects: the originator of the action; the recipient of the action; the subject is neither the doer nor the receiver, but the subject of the description, judgment, and description of the predicate. Pan (1997) in "English-Chinese contrast outline" divided the subject into four kinds, namely, the doer subjects, the receiver subjects, theme subjects, and formal subjects. From the examples and explanations given in the book, it can be seen that Pan's "thematic subject" is basically same as Huang's "neutral subject," containing the same concept. From this, we know English and Chinese subject types are nearly the same, only the 'formal subject' is the 'specialty' of English. It is clear that there is no agent in the sentence of a structurally inanimate subject because it is impossible for an inanimate subject to perform an action or actions. In this way, structural inanimate subject sentences can be divided into three subcategories: inanimate neutral subject sentences, inanimate subject statement sentences, and inanimate formal subject sentences.

\subsubsection{Inanimate Neutral Subject Sentences}

The inanimate neutral subject sentence refers to the inanimate subject that acts as the subject of description, judgment, and explanation in the sentence. According to the category and semantic characteristics of its predicate verb, this kind of sentence can be shown as the following four types:

1) $\mathrm{S}+$ link $\mathrm{V}+\mathrm{C}$

For example:

(1) A spade and a rake are necessary tools for this work.

(2) Your ideal is unrealistic.

In this sentence pattern, the connective verbs can only be, seem, appear, etc. If we use other connective verbs, such as sound, look, feel, smell, taste, lie, stand, etc., we can count them as metaphorical sentences because then the sentence will have a metaphorical meaning.

2) $\mathrm{S}+\mathrm{Vi}$.

For example:

(3) The rain stopped but the snow continued.

(4) Traffic accidents happen frequently on this road.

The intransitive verbs in this sentence pattern generally reflect the occurrence, continuation or termination of natural phenomena or events. Common verbs of this kind include: start, begin, rise, fall, occur, approach, coincide, suffice, elapse, collapse, and so on.

3) $\mathrm{S}+\mathrm{Vt} .+\mathrm{O}$

For example:

(5) The appointment slipped my memory.

(6) Tractors facilitate farming.

In this sentence pattern, the transitive verb generally states the fact and contains the causative meaning. It must be used in conjunction with the inanimate subject. Common verbs of this kind include: cost, elude, embody, exemplify, defy, symbolize, suffice and so on.

4) $\mathrm{S}+\mathrm{Vt} .+\mathrm{O}$ (sb.)

For example:

(7) Darkness frightens children.

(8) His answer puzzled me. 
A transitive verb in the sentence pattern generally shows a state of mind or feeling, because the inanimate subjects represent a kind of phenomenon of the sentence, and the object is the recipient of this phenomenon, it is also called the object experiential verb. Common verbs of this kind include: amaze, amuse, delight, dismay, horrify, perplex, surprise, thrill, upset, vex, frustrate, irritate, remind, convince and so on.

\subsubsection{Inanimate Subject Statement Sentences}

Inanimate subject sentences are usually generated by the passive voice of the animate transitive verbs. This kind of sentence is less difficult to be understood.

For example:

(9) The plan will soon be examined.

(10) The colorful flowers were seen everywhere in the spring.

It should be noted that not all passive voices of animate transitive verbs can generate inanimate subject sentences. For example, passive voices such as object experiential verbs or double object transitive verbs rarely produce inanimate subject sentences.

\subsubsection{Inanimate Formal Subject Sentences}

As mentioned above, the formal subject is a 'specialty' of English, but there is no such concept in Chinese. In fact, the formal subjects are inanimate subjects. Thus, the inanimate formal subject sentence is semantically repetitive but has to be called here for the purposes of classification in order to distinguish-it from the other two inanimate subject sentences. Inanimate subject sentences can also be divided into two types, whose manifestations are complex, as illustrated by the following examples.

1) Inanimate formal subject sentences guided by ' $\mathrm{It}$ '

There are five situations in which ' $I t$ ' leads to an inanimate form.

A. 'It' as the subject, refers to time, distance, weather, and the natural environment such as abstract concepts, mentioned things or concepts, or the context of complex words with no other real subject.

For example:

(11) It is six o'clock now, it is clearing up and it is quiet everywhere.

(12) It is going to be an increased satisfaction to our customers if we are happy.

B. 'It' as the formal subject, the infinitive phrase is the real subject of the sentence.

For example:

(13) It does my heart good and it gives me pleasure to confide a little in you.

(14) It is his fate to leave here in the evening.

C. 'It' as the formal subject, the gerund phrase as the real subject of the sentence.

For example:

(15) It is no use explaining the reason to him.

(16) It is no fun flying the kites.

D. 'It' as the formal subject, the subject clause is the real subject of the sentence.

For example: (17) It is reported that the president will visit China in June.

(18) It does not matter whether he goes to the cinema or not.

(Of course, the infinitive phrase, gerund phrase, or the subject subordinate clause can also be referred to without formal subject "It", and directly as the subject to generate inanimate subjects sentences.)

E. 'It' as the formal subject to form the emphatic sentence.

For example:

(19) It was Mike who met your cousin in the theatre yesterday.

(20) It is in the gym that he often plays basketball.

2) Inanimate formal subject sentences guided by 'There'

People have different interpretations of the sentence pattern 'There + be'. Traditional grammar regards indefinite nouns or noun phrases behind 'be' as subjects and 'there' as guides. In Halliday's systemic functional grammar, 
'there' is regarded as an empty subject or dummy subject, and the verb 'be' embodied the process of existence.

For example:

(21) There were staring eyes and dropping jaws all around us.

(22) There was a moment of throbbing suspense.

\section{Semantic Characteristics of Inanimate Subject Sentences}

Two subcategories of metaphorical inanimate subject sentences mentioned above, according to the semantic characteristics of the embodiment of life, metaphorical inanimate subject sentences can be classified into ideational metaphor inanimate subject sentences (from conceptual metaphor) and grammatical metaphor inanimate subject sentences (from grammatical metaphor). Here, according to the semantic characteristics of the two types of inanimate subjects, this paper will give examples to illustrate their different sentence patterns.

\subsection{Conceptual Metaphor Sentences with Inanimate Subjects}

As mentioned above, such sentences are generated by the collocation of inanimate subject and animate predicate. Their new and vivid expressive effect is generated by conceptual metaphor. The core content of Lakoff's conceptual metaphor theory is the principle of cross-domain mapping, that is, in the process of people knowing the world, there are always two cognitive domains, and the concepts in one domain are always mapped to the other domain. In terms of the inanimate subject sentences we are discussing, the process of conceptual metaphor is to map the concepts in the (predicate) life cognitive domain to the (subject) non-life cognitive domain, so that inanimate things or concepts can acquire the semantic characteristics of life. This is also the personification figure of speech in traditional rhetoric. Such inanimate subjects can be concrete objects or abstract concepts such as time, place, etc.

For example:

(23) A good idea suddenly struck me.

(24) Beijing has witnessed many changes in the past few years.

(25) His presence of mind never deserted him.

\subsection{Grammatical Metaphor Sentences with Inanimate Subjects}

In a sense, this kind of sentence should be summed up in the category of structurally inanimate subject sentences, because it actually embodies the way of 'grouping the parts into a whole' in English. However, since the generation of such sentences is entirely dependent on the grammatical metaphor elaborated by Halliday (1994), we classify the resulting inanimate subject sentences into the category of metaphorical inanimate subject sentences. As mentioned above, these sentences are superficially composed of inanimate subject and inanimate predicate, but in fact, the semantic characteristics of life in sentences are vividly reflected, which is a kind of metaphor in itself on one hand, On the other hand, nominalization is the core of grammatical metaphor. Nominalization refers to the conversion of verbs or adjectives into nouns, i.e. nouns are used instead of verbs or adjectives to express entities, and processes or attributes are embodied as participants. Obviously, the nouns that serve as the inanimate subjects are all nouns generated from nouns. They are seemingly abstract inanimate nouns, but they still retain some of the semantic characteristics of the relevant verbs or adjectives. With the mutual mapping between the adjectives and the adjectives, the life semantic features are shown.

For example:

(26) The punishment of the worker preceded the master's arrival.

(27) The discovery of a gun in his possession leads to the suspicion of his being the murderer.

(28) The visibility of his impatience was very great.

\section{Examples of Sentences with Inanimate Subjects}

\subsection{Countable Nouns}

The subject of this kind of sentence is usually some nouns expressing things. The predicate of this kind of inanimate subject sentence is often acted by some animate verbs, which makes the sentence have personification rhetoric effect, makes the language more vivid and gives people a kind of association.

(29) Your idea sounds reasonable. 你的想法听起来很合理。

(30) The accident happened last night. 昨晚发生了一起事故。

(31) Several letters arrived this morning. 今天上午来了几封信。 


\subsection{Uncountable Nouns}

Uncountable nouns include material nouns, abstract nouns and proper nouns, which are widely used as subjects of English inanimate subject sentences. There are many kinds of discussions about uncountable nouns. Only abstract nouns are concretely discussed.

\subsubsection{Time, Place, Number as Subjects}

This sentence pattern usually takes the nouns of time or place as the subject, such as 'Taizhou', 'China', or '2009' in sentences below. The predicate is usually 'see', 'witness', 'hold', and other animate verbs.

(31) The past 30 years have seen the rapid development of Chinese economy. 在过去的 30 年里, 中国的经济 飞速发展。

(32) China witnessed many great historical events. 在中国发生了许多重大历史事件。

(33) 2009 saw the holding of the Music Festival in Taizhou. 2009 年, 泰州举办了音乐节。

\subsubsection{Physical and Mental State, or an Encounter as Subjects}

The subject of this inanimate subject sentence is usually an abstract noun expressing emotional state, such as sadness, anger, anxiety, etc. Verbs used as predicates are usually personified animated verbs.

(34) Sad without a repayment, it is forced to hire. 伤心是不可能一次偿还干净的, 它是被迫分期付款的。

(35) Anxiety tore her into pieces. 她焦虑不安,全身崩溃了。

(36) Anger rests in the bosom of folly. 怒火常常占据蚌人的胸中。

\subsubsection{Specific Behavior and Action with Verb Meanings as Subjects}

This kind of inanimate noun is usually the noun form of the verb (such as sight, arrival, etc.) or the noun with verb meaning (idea, thought, etc.). These words usually form the subject of the inanimate subject sentence together with other modifiers, and form a logical subject-predicate or verb-object relationship with the modifiers before and after them.

(37) Accept what was and what is, and you'll have more positive energy to pursue what will be. 接受过去和现 在的模样, 才会有能量去追寻自己的未来。

(38) His unexpected arrival alarmed all of us. 他不期而至,我们都很惊讶。

(39) Trust is the easiest thing in the world to lose, and the hardest thing in the world to get back. 信任是这个世 界上最容易失去的东西, 也是最难挽回的东西。

\subsection{The '-ing' Participle}

The '-ing' here is a gerund in traditional grammar. The subject of the '-ing' participle as an inanimate subject is usually an abstract action.

(40) Teaching is a meaningful job. 教学是一项有意义的工作。

(41) Learning from your mistakes is a good way to learn English. 错误中学习是学习英语的好方法。

(42) Swimming is good for our health. 游泳有益于身体健康。

\subsection{The Form of ' $I t$ '}

Because English has the tendency of nominal, many people take the non-personal pronoun 'it' as their main subject. The functions and semantics of 'it' can be summarized into three categories: unspecified word, preparatory word and cleft sentence. 'It' as a formal subject generally refers to all things (situations) or plays a certain syntactic function to make the sentence grammatical integrity, or plays an emphasizing role, in order to enhance the mood.

(43) It appears that Mr. Jackson has got religion on the subject of environmentalism. 杰克逊先生在环保问题上 似乎终于醒悟过来了

(44) It is a good idea to go shopping. 去购物是一个很好的主意。

(45) It does not matter how slowly you go as long as you do not stop. 前进缓慢没关系, 只要你别停下脚步。

\section{Conclusion}

As the carrier of expressing thoughts and expressing emotions, language is bound to embody the unique philosophical background and thinking mode of each nation in its structure and expression. Chinese and English have great differences, which will make the translation of English inanimate subject sentences challenging and 
excessively difficult. In the paper, some preliminary discussion on the inanimate subject sentence and on translation is carried out. As noted, as a kind of artistic recreation, the method of translation is not invariable, and there are exceptions to any rule. This requires experience accumulated in practice, the principles to be mastered, and efforts made in the translation faithful to the original text and in conformity to the expression of the target language.

\section{References}

Comrie, B. (1981). Language Universals and Linguistic Typology. Chicago: The University of Chicago Press.

Foley, W. A. (1997). Anthropological Linguistics. Oxford: Blackwell Publishers.

Halliday, M. A. K. (1994). An Introduction to Functional Grammar. London: Edward Arnold.

He, M. (2003). Comparison of English Inactive Subject Sentences and English-Chinese Thinking Characteristics. Journal of Zhuzhou Normal College, 4, 75-77.

He, M. (2013). A Study of English Passive Subject Proverbs. Language Education, 2, 51-55.

$\mathrm{Hu}$, S. (1993). Comparison on Rhetoric in English and Chinese. Shanghai: Shanghai Foreign Language Education Press.

Huang, B. 1983 Modern Chinese. Beijing: Higher Education Press.

Jespersen, O. (1951). The Philosophy of Grammar. London: George Allen \& Unwin Ltd.

Lakoff, G., \& Johnson, M. (1980). Metaphors We Live By. Chicago: The University of Chicago Press.

Lakoff, G., \& Turner, M. (1989). More than Cool Reason: A field guide to poetic metaphor. Chicago: The University of Chicago Press. https://doi.org/10.7208/chicago/9780226470986.001.0001

Lan, C. (2005). Cognitive Linguistics and Metaphor. Beijing: Foreign Language and Research Press.

Leech, G., \& Svartvik, J. (1975). A Communicative Grammar of English. London: Longman.

Lewis, N. (1949). Word Power Made Easy. London: Longman.

Ma, B. (1995). Exploratory Research on Differences of Subjects in Chinese and English. Foreign Language, 5(5), $55-59$.

Master, P. (1991). Active Verbs with Inanimate Subjects in Scientific Prose. English for Specific Purposes, 1, 15-33. https://doi.org/10.1016/0889-4906(91)90013-M

Pan, W. (1997). Outline of Contrast between Chinese and English Languages. Beijing: Beijing Language and Culture University Press.

Quirk, R. et al. (1985). A Comprehensive Grammar of the English Language. London: Longman Group Ltd.

Seskauskiene, I. (2009). The Paper Suggests: Inanimate Subject + Active Verb in English Linguistic Discourse. KALBOTYRA, 3, 84-93. https://doi.org/10.15388/Klbt.2009.7628

Wang, M. (1999). Comparison between English and Chinese Subjects. Foreign Language Education, 1, 87-95.

Wei, Z. (2003). Introduction to English and Chinese Contrast Research. Shanghai: Shanghai Foreign Language Education Press.

Yule, G. (2014). The Study of Language (5th ed.). Cambridge: Cambridge University Press.

Zhou, Q. (2009). A Cognitive Analysis of English Sentences with Inanimate Subjects. Journal of Shaoguan University (Social Science), 30(5), 77-79.

\section{Copyrights}

Copyright for this article is retained by the author, with first publication rights granted to the journal.

This is an open-access article distributed under the terms and conditions of the Creative Commons Attribution license (http://creativecommons.org/licenses/by/4.0/). 